\title{
Frequency of underweight in Saudi adults
}

\begin{abstract}
Background and objective: Metabolic syndrome (MetS) is a cluster of metabolic factors. The prevalence of MetS is increasing worldwide. The aim of this study was to determine the frequency of MetS in normal weight Saudi population.

Methods: We analyzed 396 participants who are equal to or older than 20years old with body mass index (BMI) between 18.5 to $24.9 \mathrm{~kg} / \mathrm{m}^{2}$. All cases were from the population of the primary health at King Fahad Armed Forces Hospital. All data were collected by personal interview and on the basis of a review of electronic medical records. Physician and nurse interviewers measured and recorded weight $(\mathrm{kg})$ and height $(\mathrm{cm})$. Metabolic risk factors were defined using the 2006 International Diabetes Federation criteria that define elevated triglyceride as $\geq 150 \mathrm{mg} / \mathrm{dL}(\geq 1.7 \mathrm{mmol} / \mathrm{L})$ and reduced $\mathrm{HDL}$ as $<40 \mathrm{mg} / \mathrm{dL}$ $(<1.03 \mathrm{mmol} / \mathrm{L})$ for male and as $<50 \mathrm{mg} / \mathrm{dL}(<1.29 \mathrm{mmol} / \mathrm{L})$ for female. Abnormal glucose metabolism was considered when HbAlc $(\geq 5.7)$ or when patients were known to have type 2 diabetes. BMI values classified as normal weight if $\mathrm{BMI}=18.5-24.9 \mathrm{~kg} / \mathrm{m}^{2}$. The total number of cohort was separated on basis of age values into five groups: <30years, 30-39years, 40-49years, 50-59years and $\geq 60$ years.
\end{abstract}

Main results: Of the 396 participants analyzed, 158 (39.9\%) were male and $238(60.1 \%)$ were female. Age was 51.6 \pm 16.3 (minimum 20years and maximum 98 years). MetS was present in 198 cases $(50.0 \%)$ where $89(44.9 \%)$ were male and $109(55.1 \%)$ were female with female to male ratio $1.2: 1, \mathrm{P}=0.04$. Patients were significantly older in MetS patients $58.1 \pm 14.0$ vs. $44.9 \pm 15.6$ respectively, $\mathrm{p}<0.0001$. BMI was not significantly higher in females than males with MetS patients $(22.9 \pm 1.5$ vs. $22.6 \pm 1.7$ respectively, $\mathrm{p}<0.0001)$. Patients with $\mathrm{HbA} 1 \mathrm{c}>5.6$ or Type 2 diabetes mellitus were 4 -fold to possess MetS [OR=4.9; $95 \%$ confidence interval $[\mathrm{CI}]=3.2,7.4$, $(\mathrm{p}<0.0001)]$, or have elevated plasma TG levels $(\mathrm{OR}=2.6 ; 95 \% \mathrm{CI}=2.2,3.1, \mathrm{p}<0.0001)$ and were also more likely to have low levels of HDL $(\mathrm{OR}=2.4 ; 95 \% \mathrm{CI}=2.0,3.0, \mathrm{p}<0.0001)$. The frequency of MetS is consistently increasing with increasing age until the sixth decade. MetS is more frequent in male at the age group ( $\geq 60$ years). The frequency of MetS is consistently increasing with increasing BMI with male predominant. The mean of BMI among MetS is not statistically significant positively correlated with increasing with advanced age $(r=0.1, p=0.4)$.

Conclusion: It can be concluded from this study that the frequency of MetS among normal weight Saudis is relatively high. Old age and higher normal body weight can be regarded as related factors.

Keywords: metabolic syndrome, normal body mass index, CI, MetS, HDL
Volume 8 Issue $6-2018$

\author{
Khalid S Aljabri MD,' Samia A Bokhari \\ MD,' Muneera A Alshareef MD,' Patan M \\ Khan MD,' Hesham M AbuElsaoud MD,' \\ Mohammad M Jalal MD,' Rania F Safwat MD,' \\ Rehab El Boraie MD,' Nawaf K Aljabri MLT,' \\ Bandari K Aljabri MS, ${ }^{3}$ Arwa Y Alsuraihi MS, ${ }^{3}$ \\ 'Department of Endocrinology, King Fahad Armed Forces \\ Hospital, Jeddah, Kingdom of Saudi Arabia \\ 2 Department of Laboratory, Northern Armed Farces Hospital, \\ Hafr Al-Batin, Kingdom of Saudi Arabia \\ ${ }^{3}$ College of medicine, Um Al Qura University, Makkah, Kingdom \\ of Saudi Arabia
}

Correspondence: Khalid SJ Aljabri, MD, FRCPC, FRCPC(Endo), FACP,ABIM, ABEM, Department of Endocrinology, King Fahad Armed Forces Hospital, PO Box 9862, Jeddah 21159, Kingdom of Saudi Arabia, Fax +966(02)5760665, Tel +966590008035, Email khalidsaljebri@yahoo.com

Received:September 14, 2018 | Published: November 07, 2018

\section{Introduction}

Metabolic syndrome (MetS) is a cluster of metabolic factors. MetS was initially observed in 1923 by Kyln, who described the clustering of hypertension, hyperglycaemia and gout as the syndrome. ${ }^{1}$ The first official definition of MetS put forward by a working group of the World Health Organization (WHO) in 1999, a number of different definitions have been proposed. There have been several definitions of MetS, but the most commonly used criteria for definition at present are from the National Cholesterol Education Program (NCEP) Adult Treatment Panel III (ATP III), the International Diabetes Federation (IDF), and the World Health Organization (WHO). ${ }^{2-4}$

Body mass index (BMI) and waist circumference are two most popular indicators for assessing obesity, which are relatively inexpensive and easy to use. BMI is strongly associated with body fat content, but has the limitation of overestimating the degree of fatness for very muscular man and underestimating those who have low muscle mass, as in the case of elderly people. In addition, there is gender, age, and ethnicity related variations in body fat for a given BMI. Over 30 years ago, metabolic disorders were observed in some patients with normal BMI $\left(18.5-24.9 \mathrm{~kg} / \mathrm{m}^{2}\right)$, similar to disorders which characterized obese individuals. Such patients were described as being a metabolically obese normal weight (MONW) phenotype. $^{5}$ In these individuals, an increase in visceral adipose tissue mass, fasting hyperglycemia, lower insulin sensitivity of target tissues, hyperinsulinemia, atherogenic dyslipidemia, high arterial pressure, fatty liver, and greater plasma proinflammatory cytokine concentrations are usually diagnosed..$^{5-7}$

Due to the lack of uniform criteria for identification of a MONW phenotype, and examination of different ethnic and age groups, it is difficult to make an actual assessment of the scale of the problem..$^{5-12}$ In a longitudinal study, identified this syndrome only in $7.1 \%$ of those who had BMI $<25 \mathrm{~kg} / \mathrm{m}^{2}{ }^{6}$ The occurrence of MONW in $20.4 \%$ of males and $23.8 \%$ of females aged $45-74$ was reported. ${ }^{13}$

Early identification of individuals at risk is additionally hindered because of the lack of uniform diagnostic criteria of MONW. Therefore, this issue requires further examination. Therefore, the objective of the study was to assess the frequency of MetS in normalweight Saudis. 


\section{Methods}

We analyzed 396 participants who are equal to or older than 20years old with BMI between 18.5 to $24.9 \mathrm{~kg} / \mathrm{m}^{2}$. All cases were from the population of the primary health at King Fahad Armed Forces Hospital. All data were collected by personal interview and on the basis of a review of electronic medical records. Physician and nurse interviewers measured and recorded weight $(\mathrm{kg})$ and height (cm). Metabolic risk factors were defined using the 2006 IDF criteria that define elevated triglyceride as $\geq 150 \mathrm{mg} / \mathrm{dL}(\geq 1.7 \mathrm{mmol} / \mathrm{L})$ and reduced HDL as $<40 \mathrm{mg} / \mathrm{dL}(<1.03 \mathrm{mmol} / \mathrm{L})$ for male and as $<50 \mathrm{mg} /$ $\mathrm{dL}(<1.29 \mathrm{mmol} / \mathrm{L})$ for female. Abnormal glucose metabolism was considered when $\mathrm{HbAlc}(\geq 5.7)$ or when patients were known to have type 2 diabetes. BMI values classified as normal weight if $\mathrm{BMI}=18.5-$ $24.9 \mathrm{~kg} / \mathrm{m}^{2}$. The total number of cohort were separated on basis of age values into five groups: $<30$ years, $30-39$ years, $40-49$ years, 50-59 years and $\geq 60$ years.

\section{Statistical analysis}

Unpaired t-test analysis and Chi square $\left(\mathrm{X}^{2}\right)$ test (categorical data comparison) were used between variables to estimate the significance of different between groups for demographic and clinical laboratory. Odds ratio of having MetS was analyzed using Chi square $\left(\mathrm{X}^{2}\right)$. All statistical analyses were performed using SPSS Version 22.0. The difference between groups was considered significant when $\mathrm{P}<0.05$.

\section{Results}

Of the 396 participants analyzed, 158(39.9\%) were male and Table 2 Characteristics of the population with metabolic syndrome (means \pm SD or number (\%))

\begin{tabular}{|c|c|c|c|}
\hline \multirow{2}{*}{ Parameters } & \multicolumn{2}{|c|}{ Metabolic syndrome } & \multirow{2}{*}{$P$ value } \\
\hline & Yes & No & \\
\hline n (\%) & $328(30.9)$ & $732(69.1)$ & 0.7 \\
\hline Age (years) & $58.1 \pm 14.0$ & $44.9 \pm 15.6$ & $<0.0001$ \\
\hline \multirow{2}{*}{$\begin{array}{l}\text { Male } \\
\text { Female }\end{array}$} & $89(44.9)$ & $69(34.8)$ & \multirow{2}{*}{0.04} \\
\hline & $109(55.1)$ & $129(65.2)$ & \\
\hline Body mass index $\left(\mathrm{kg} / \mathrm{m}^{2}\right)$ & $22.9 \pm 1.5$ & $22.6 \pm 1.7$ & 0.1 \\
\hline HbAlc $>5.6$ or Type 2 diabetes mellitus & $178(89.9)$ & $78(39.4)$ & $<0.0001$ \\
\hline Triglyceride $(\geq 1.7 \mathrm{mmol} / \mathrm{l})$ & $101(51.0)$ & II (5.6) & $<0.0001$ \\
\hline High density lipoprotein $(<1.29 \mathrm{mmol} / \mathrm{l})$ & $127(64.1)$ & $4 \mid(20.7)$ & $<0.000$ I \\
\hline
\end{tabular}

Table 3 shows patients HbA1c $>5.6$ or Type 2 diabetes mellitus with were 4-fold to possess MetS [OR=4.9; 95\% confidence interval $[C I]=3.2,7.4, \quad(p<0.0001)]$, or have elevated plasma TG levels $(\mathrm{OR}=2.6 ; 95 \% \mathrm{CI}=2.2,3.1, \mathrm{p}<0.0001)$ and were also more likely to have low levels of $\operatorname{HDL}(\mathrm{OR}=2.4 ; 95 \% \mathrm{CI}=2.0,3.0, \mathrm{p}<0.0001)$.

The frequency of MetS is consistently increasing with increasing age until the sixth decade, Figure 1A. MetS is more frequent in male at the age group ( $\geq 60$ years), Figure $1 \mathrm{~B}$. The frequency of MetS is consistently increasing with increasing BMI, Figure 2A with male predominant, Figure 2B. The mean of BMI among MetS is not statistically significant positively correlated with increasing with advanced age $(r=0.1, p=0.4)$.
238(60.1\%) were female. Age was 51.6 \pm 16.3 (minimum 20 years and maximum 98years), Table 1. MetS was present in 198 cases $(50.0 \%)$ where $89(44.9 \%)$ were male and $109(55.1 \%)$ were female with female to male ratio $1.2: 1, \mathrm{P}=0.04$, Table 2 . Patients were significantly older in MetS patients $(58.1 \pm 14.0$ vs. $44.9 \pm 15.6$ respectively, $\mathrm{p}<0.0001)$. BMI was not significantly higher in females than males with MetS patients ( $22.9 \pm 1.5$ vs. $22.6 \pm 1.7$ respectively, $\mathrm{p}<0.0001)$. Patients with MetS were significantly higher $\mathrm{HDL}$ and $\mathrm{HbAlc}>5.6$ or triglyceride $(\geq 1.7 \mathrm{mmol} / \mathrm{l})$, Table 2 .

Table I Basic characteristics of the population under study (means \pm SD or number $(\%)$ )

\begin{tabular}{|c|c|}
\hline Parameters & Total \\
\hline n (\%) & 396 \\
\hline Age (years) & $51.6 \pm 16.3$ \\
\hline \multirow{2}{*}{ Gender } & $158(39.9)$ \\
\hline & $238(60.1)$ \\
\hline Body mass index $\left(\mathrm{kg} / \mathrm{m}^{2}\right)$ & $22.8 \pm 1.6$ \\
\hline HbA Ic $>5.6$ or Type 2 diabetes mellitus & $256(64.6)$ \\
\hline Triglyceride $(\geq 1.7 \mathrm{mmol} / \mathrm{l})$ & $112(28.3)$ \\
\hline High density lipoprotein $(<1.29 \mathrm{mmol} / \mathrm{l})$ & $168(42.4)$ \\
\hline
\end{tabular}

Table 3 The risk of metabolic syndrome phenotype

\begin{tabular}{lll}
\hline Parameters & Odd Ratio & P value \\
\hline HbA Ic $>5.6$ or Type 2 diabetes mellitus & $4.9(3.2-7.4)$ & $<0.000$ I \\
Triglyceride $(\geq 1.7 \mathrm{mmol} / \mathrm{I})$ & $2.6(2.2-3.1)$ & $<0.000$ I \\
High density lipoprotein $(<1.29 \mathrm{mmol} / \mathrm{l})$ & $2.4(2.0-3.0)$ & $<0.000 \mathrm{I}$
\end{tabular}




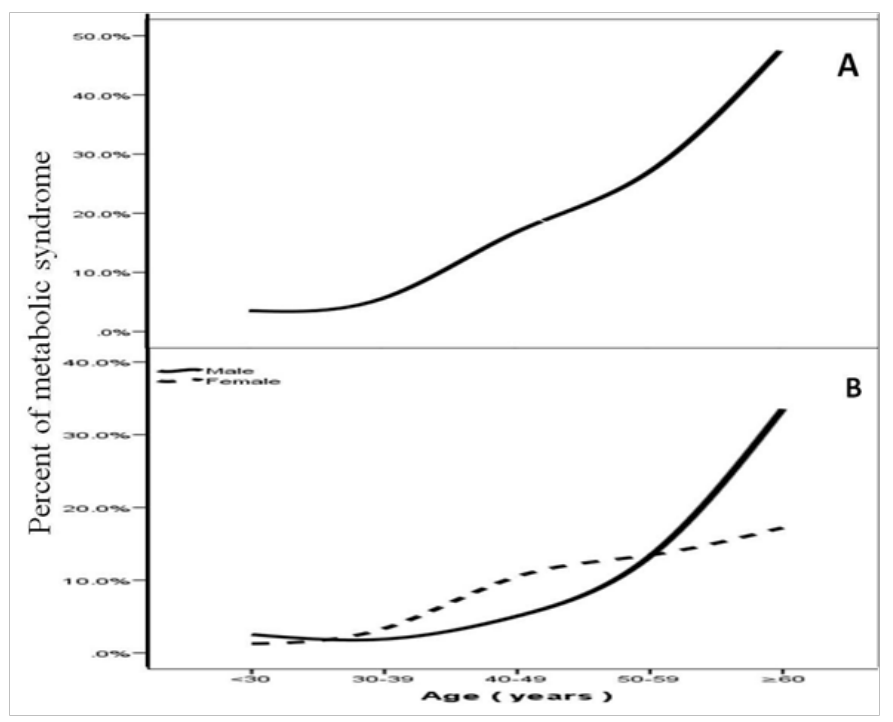

Figure I (A) Percentages of metabolic syndrome across different age groups and $(B)$ in relation to gender.

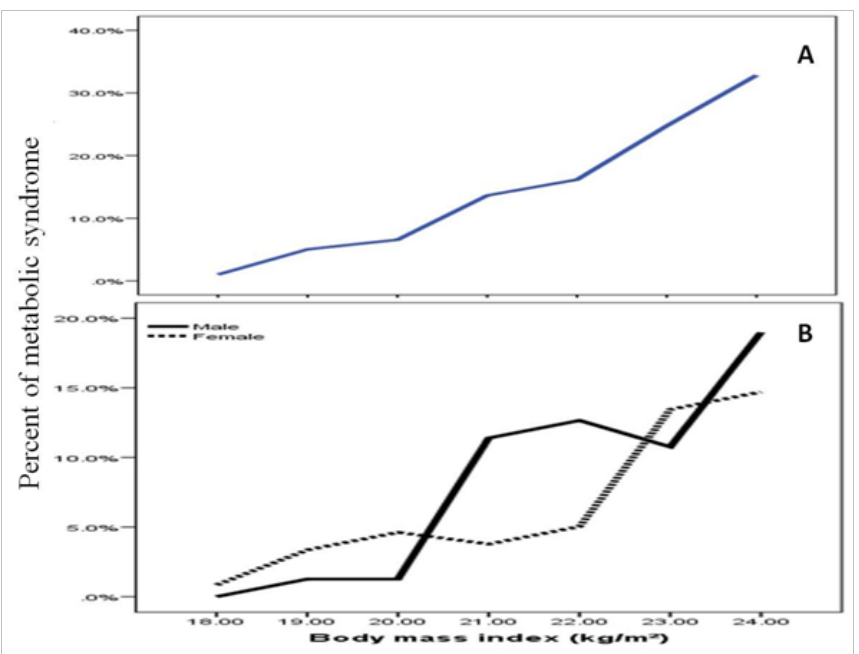

Figure 2 (A) Percentages of metabolic syndrome across different body mass index groups and $(B)$ in relation to gender.

\section{Discussion}

We found that MetS was present in $50.0 \%$ of the total number of participants, 89 cases $(44.9 \%)$ of males; 109 cases $(55.1 \%)$ of females. This percentage should be considered as relatively high, considering the accepted definition of the syndrome, i.e. $\mathrm{BMI}<25.0$ $\mathrm{kg} / \mathrm{m}^{2}$, but not $<26-27 \mathrm{~kg} / \mathrm{m}^{2}$ as adopted by many other researchers. ${ }^{10}$ In previous studies, MetS - defined according to the IDF-was diagnosed in $12.3 \%, 30.75 \%$ of males and $26.8 \%$ of females. However, these studies concerned a much younger population, starting from the age of 20years. ${ }^{14,15}$ Such a high percentage of individuals with MetS reported in our study resulted mostly from the sample selection. It was an open research; therefore, the study group could have covered an overrepresentation of individuals in whom the frequency of occurrence of MetS risk factors was higher than in the general population. In addition, the frequency of MetS is consistently increasing with increasing age until the sixth decade, dominated those aged $\geq 60$ years. We found the occurrence of MetS increases together with age, from $3.5 \%$ in the age group $20-29$ to $47.5 \%$ in the age group $\geq 60$. According to the result of studies conducted in the USA, the occurrence of MetS increases together with age, from $6.7 \%$ in the age group $20-29$ to $43.5 \%$ in the age group $60-69$, and $42 \%$ in the group of individuals aged 70 and over. ${ }^{16}$

In the early eighties, a specific type of obesity defined as metabolically obese normal weight subjects (MONW) was described. ${ }^{17}$ These individuals were characterized by normal body weight and BMI, but presented hyperinsulinemia, insulin resistance, and increased type 2 diabetes, hypertriglyceridemia and cardiovascular diseases predisposition. ${ }^{18,19}$ In a study of the US population, individuals aged 20 years with MONW were four times more likely to develop MetS than those with normal BMI. ${ }^{18}$ In another study carried out in Switzerland, which included only females of Caucasian origin aged 35-75years, women with MONW had a higher cardiometabolic risk and higher prevalences of low HDL-cholesterol, high waist circumference, high triglycerides and hyperglycaemia but a similar prevalence of hypertension compared to lean women. ${ }^{20}$

In this report, we advance the notion that MONW individuals are those with a normal BMI who fulfill the criteria for the MetS as defined by the ATP III guidelines. We observed that men and women in the normal BMI range are more likely to have the MetS compared with those with BMI $18.5-20.9 \mathrm{~kg} / \mathrm{m}^{2}$. The phenomenon could only partially be explained by their older age. It is well known that for a given BMI, older persons often have more fat than younger persons, and women may have more body fat than men. Our age and genderspecific MetS prevalence data not only support this view, but also depict an even more apparent age and gender associated pattern of abdominal fat accumulation. This phenomenon is consistent with previous study. ${ }^{21,22}$ Individual risk factors of may differ between males and females and, therefore, contribute to gender-related differences in the risk of metabolic complications, such as insulin resistance..$^{23}$ Despite the fact that the total frequency of occurrence of MONW was noted in both genders, an increased risk of this syndrome was noted among females with considerably lower BMI values. Several studies showed higher body fat (especially visceral depot) and low lean mass in the metabolically obese normal-weight individuals. ${ }^{23,24}$

The other aspect of our data that we found interesting was that, in this study population that may be considered non-obese by existing recommendations $\left(\mathrm{BMI}<25 \mathrm{~kg} / \mathrm{m}^{2}\right)$, the features of the MetS remained very common with over half exhibiting at least one feature of the MS. This is in line with the finding that BMI significantly underestimates the degree of adiposity in several Asian populations and the recommendation that lower 'action levels' should be set in this populations. ${ }^{25}$

This underpins the importance of estimating the country-specific prevalence of MetS. One reason for this finding is that the population of Saudi Arabia is changing from its traditional lifestyle to westernised ways and so becoming more subject to similar diseases, the young being more prone in this regard. In contrast, older people, who are less inclined to change their habits, reflected healthier findings. It would be beneficial to identify lifestyle changes among the elderly that could determine the increased tendency to develop risk factors for the diseases of developed countries. It would also be interesting to determine to what extent these risk factors are associated with cardiovascular disease, stroke and/or type 2 diabetes among Saudi population, since most studies have been conducted in Caucasian populations.

\section{Limitations}

Our results should be interpreted in light of the study's limitations. 
First, most of the patients enrolled were already on treatment for diabetes and hypertriglyceridemia, which imposed some limitations on the study. We tried to overcome these by obtaining the necessary sample size and by using data documented before treatment. Finally, as this was a hospital-based, retrospective study, the findings do not represent the whole Saudi population or the local community. Further larger population-based studies are necessary to support our findings. Another limitation of the present study was having considered only overall normal weight (assessed by BMI) and not abdominal obesity (measured by waist circumference), which is known to bear a close relationship with the target diseases.

\section{Conclusion}

It can be concluded from this study that the frequency of MetS among normal weight Saudis is relatively high. Old age and higher normal body weight can be regarded as related factors.

\section{Acknowledgments}

We are grateful to the staffs from the Primary care department at King Fahad Armed Forces Hospital for their valuable contributions in data collection. The authors have no conflict of interest to disclose.

\section{Conflict of interest}

Authors declare that there is no conflict of interest.

\section{References}

1. Kylin E. Studien ueber das Hypertonie-Hyperglykamie -Hyperurikamiesyndrom. Zentrallblatt fuer Innere Medizin. 1923;44(81):105-127.

2. National Cholesterol Education Program (NCEP). Third Report of the National Cholesterol Education Program (NCEP) Expert Panel on Detection, Evaluation, and Treatment of High Blood Cholesterol in Adults (Adult Treatment Panel III) Final Report. Circulation.2002;106(25):3143-3421.

3. International Diabetes Federation. The IDF Consensus Worldwide Definition of the Metabolic Syndrome. Belgium: IDF; 2006.

4. World Health Organization. Definition, Diagnosis and Classification of Diabetes Mellitus and its Complications. Report of a WHO Consultation. Part 1: Diagnosis and Classification of Diabetes Mellitus, Department of Non-communicable Disease Surveillance. Switzerland: Geneva; 1999.

5. Ruderman N, Chisholm D, Pi-Sunyer X, et al. The metabolically obese, normal-weight individual revisited. Diabetes. 1998;47(5):699-713.

6. Meigs JB, Wilson PW, Fox CS, et al. Body mass index, metabolic syndrome, and risk of type 2 diabetes or cardiovascular disease. J Clin Endocrinol Metab. 2006;91(8):2906-2912.

7. Hyun YJ, Koh SJ, Chae JS, et al. Atherogenecity of LDL and unfavorable adipokine profile in metabolically obese, normal-weight woman. Obesity (Silver Spring). 2008;16(4):784-789.

8. Dvorak RV, DeNino WF, Ades PA, et al. Phenotypic characteristics associated with insulin resistance in metabolically obese but normal-weight young women. Diabetes. 1999;48(11):2210-2214.
9. Romero-Corral A, Somers VK, Sierra-Johnson J, et al. Normal weight obesity: a risk factor for cardiometabolic disregulation and cardiovascular mortality. Eur Heart J. 2010;31(6):737-746.

10. Park YW, Zhu S, Palaniappan L, et al. The metabolic syndrome: prevalence and associated risk factor findings in the US population from the Third National Health and Nutrition Examination Survey, 1988-1994. Arch Intern Med. 2003;163(4):427-436.

11. Geetha L, Deepa M, Anjana RM, et al. Prevalence and clinical profile of metabolic obesity and phenotypic obesity in Asian Indians. $J$ Diabetes Sci Technol. 2011;5(2):439-446.

12. Lopez-Miranda J, Perez-Martinez P. It is time to define metabolically obese but normal-weight (MONW) individuals. Clin Endocrinol (Oxf). 2013;79(3):314-315.

13. Pajunen P, Kotronen A, Korpi-Hyövälti E, et al. Metabolically healthy and unhealthy obesity phenotypes in the general population: the FIND2D Survey. BMC Public Health. 2011;11:754.

14. Sygnowska E, Piwońska A, Waśkiewicz A, et al. Socioeconomic factors and the risk of metabolic syndrome in the adult Polish population: the WOBASZ study. Kardiol Pol. 2012;70(7):718-727.

15. Suliga E, Kozieł D, Głuszek S. Prevalence of metabolic syndrome in normal weight individuals. Ann Agric Environ Med. 2016;23(4):631-635.

16. Ford ES, Giles WH, Dietz WH. Prevalence of the metabolic syndrome among US adults: findings from the Third National Health and Nutrition Examination Survey. JAMA. 2002;287(3):356-359.

17. Ruderman NB, Schneider SH, Berchtold P. The "metabolically-obese," normal-weight individual. Am J Clin Nutr. 1981;34(8):1617-1621.

18. Romero-Corral A, Somers VK, Sierra-Johnson J, et al. Normal weight obesity: a risk factor for cardiometabolic dysregulation and cardiovascular mortality. Eur Heart J. 2010;31(6):737-746.

19. De Lorenzo A, Martinoli R, Vaia F, et al. Normal-weight obese (NOW) women: An evaluation of a candidate new syndrome. Nutr Metab Cardiovasc Dis. 2006;16(8):513-523.

20. Marques-Vidal P, Pécoud A, Hayoz D, et al. Normal weight obesity: relationship with lipids, glycaemic status, liver enzymes and inflammation. Nutr Metab Cardiovasc Dis. 2010;20(9):669-675.

21. Stevens J, Knapp RG, Keil JE, et al. Changes in body weight and girth in black and white adults studied over a 25 year interval. Int $J$ Obes. 1991;15(12):803-808.

22. Perissinotto E, Pisent $\mathrm{C}$, Sergi G, et al. Anthropometric measurements in the elderly: age and gender differences. Br J Nutr. 2002;87(2):177-186.

23. Beigh SH, Jain S. Prevalence of metabolic syndrome and gender differences. Bioinformation. 2012;8(13):613-616.

24. Tanaka S, Togashi K, Rankinen T, et al. Is adiposity at normal body weight relevant for cardiovascular disease risk? Int J Obes Relat Metab Disord. 2002;26(2):176-183.

25. Deurenberg P, Deurenberg-Yap M, Guricci S. Asians are different from Caucasians and from each other in their body mass index/body fat percent relationship. Obes Rev. 2002;3(3):141-146. 